\title{
"MEU AMIGO NIETZSCHE": OS PERIGOS DA LEITURA CRÍTICA EM UM MUNDO CONFORMADO
}

\author{
"MY FRIEND NIETZSCHE": THE DANGERS OF CRITICAL \\ READING IN A CONFORMED WORLD
}

\section{Giulia Mendes Gambassi`}

\section{RESUMO}

O objetivo deste artigo é discutir o ensino de literatura no Brasil a partir da análise do curtametragem Meu amigo Nietzsche (2012), que representa, a nosso ver, um discurso de resistência no cenário de crise democrática em que vivemos. O filme apresenta a história de Lucas, um menino da periferia de Brasília que encontra dificuldades de leitura na vida escolar e, advertido pela professora, tenta melhorar suas práticas por iniciativa própria. Ao se deparar com um exemplar de Assim falou Zaratustra (NIETZSCHE, [1883] 2011), Lucas parece desenvolver práticas de letramento crítico a partir de um processo de descoberta dos sentidos das palavras, que evoluiu para uma reflexão filosófica sobre o mundo a seu redor. Assim, a partir da análise de algumas cenas do curta-metragem, tencionamos refletir sobre a literatura e seu ensino, assim como sobre a recepção da leitura crítica em um mundo conformado.

Palavras-chave: letramento crítico; meu amigo Nietzsche; ensino de literatura; leitura subjetiva.

\section{ABSTRACT}

This article aims to discuss literature teaching in Brazil with the analysis of the short film Meu amigo Nietzsche (2012). In our perspective, this film presents a discourse of resistance in the scenario of democratic crisis we are living. The film presents the story of Lucas, a boy from the periphery of Brasilia who has reading difficulties and, advised by the teacher, tries to improve his practices on his own. When he finds a copy of Assim falou Zaratustra (NIETZSCHE, [1883] 2011), Lucas seems to develop critical literacy practices in a process of discovering the meanings of words that evolved into a philosophical reflection on the world around him. Thus, from the analysis of a few scenes of the short film, we intend to reflect on literature and its teaching, as well as on the reception of critical reading in a conformed world.

Keywords: critical literacy; my friend Nietzsche; literature teaching; subjective reading.

\section{INTRODUÇÃO}

Em 2012, Fáuston da Silva lançou um curta-metragem dirigido por ele, intitulado Meu amigo Nietzsche. Nessa produção, é contada a história de Lucas, um

\footnotetext{
* Doutoranda na Universidade Estadual de Campinas, Unicamp, Campinas, SP, Brasil. giugambassi@ gmail.com

Orcid: https://orcid.org/0000-0002-8326-8189
} 
menino brasileiro que, por apresentar um desempenho escolar aquém do esperado para os padrões estabelecidos social e academicamente, tem a atenção chamada pela professora, que afirma que ele repetirá de ano caso não "melhore" suas práticas de leitura. Contextualizado na periferia de Brasília, o curta evoca possibilidades de reflexão sobre o analfabetismo funcional ${ }^{1}$ ao mesmo tempo em que nos faz ponderar sobre os perigos da leitura crítica em um mundo conformado com a superficialidade da interpretação de textos, sem desconsiderarmos os tempos de (des)governo que orientam, por meio do Ministério da Educação, os processos de ensino e aprendizagem no Brasil.

No curta, não se sabe ao certo em que ano escolar Lucas estaria, mas podemos supor que o protagonista esteja entre o sexto e o nono ano do Ensino Fundamental. Considerando esse contexto e a temática deste artigo, cabe, então, apontar o que os Parâmetros Curriculares Nacionais (PCN) preveem em relação ao ensino de leitura e de literatura, já que esse documento orienta a educação básica no Brasil e, portanto, estabelece os critérios de que se serve a professora para apontar o fracasso do aluno. Nesse sentido, no que se refere à leitura, os PCN apontam que ela deve ser um processo ativo de construção de sentidos e não apenas de extração de informações ou decodificação. Assim, o que parece ser esperado pela professora é

a leitura fluente [que] envolve uma série de outras estratégias como seleção, antecipação, inferência e verificação [...]. É o uso desses procedimentos que permite controlar o que vai sendo lido, tomar decisões diante de dificuldades de compreensão, arriscar-se diante do desconhecido, buscar no texto a comprovação das suposições feitas, etc. (BRASIL, 1997, p. 41).

Já quanto ao tópico de ensino da literatura ou da leitura literária, o documento aponta que é esperado que haja um "reconhecimento das singularidades e das propriedades compositivas que matizam um tipo particular de escrita" (BRASIL, 1997, p. 30). Dessa forma,

é possível afastar uma série de equívocos que costumam estar presentes na escola em relação aos textos literários, ou seja, tratá-los como expedientes para servir ao ensino das boas maneiras, dos hábitos de higiene, dos deveres do cidadão, dos tópicos gramaticais, das receitas desgastadas do "prazer do texto", etc. Postos de forma descontextualizada, tais procedimentos pouco ou nada contribuem para a formação de leitores capazes de reconhecer as sutilezas, as particularidades, os sentidos, a extensão e a profundidade das construções literárias (BRASIL, 1997, p. 30, grifo nosso).

1. De acordo com o Instituto Paulo Montenegro (ação social do IBOPE - Instituto Brasileiro de Opinião Pública e Estatística), "[é] considerada analfabeta funcional a pessoa que, mesmo sabendo ler e escrever algo simples, não tem as competências necessárias para satisfazer as demandas do seu dia a dia e viabilizar o seu desenvolvimento pessoal e profissional". Disponível em: https://ipm.org. br/inaf. Acesso em: jun. 2019. 
Assim, é essa ideia de literatura como algo que deve servir - criticada nos PCN - que questionamos no primeiro item deste artigo, para fazermos, no segundo, a análise do curta, levantando alguns pontos sobre o ensino de literatura e a formação de leitores críticos na atualidade. Em seguida, na conclusão, chegamos ao que compreendemos como uma emancipação do protagonista a partir dos subterfúgios de que lança mão para ler Assim falon Zaratustra, de Nietzsche ([1883] 2011). Destarte, é entre o ensino de literatura no Brasil e o evento de letramento crítico que nos mostra o curta que localizamos a discussão apresentada a seguir.

\section{DEVE A LITERATURA SERVIR?}

Dentre as diversas ponderações a serem feitas a respeito da literatura na sala de aula quando discutimos seu ensino nas escolas, há um debate sobre fazê-lo de forma a privilegiar a leitura literária (REZENDE, 2013), focando na experiência e na subjetividade (ROUXEL, 2018) implicadas nesse processo, ou a sua sistematização, mais voltada à teoria, à crítica e à história literária (DALVI, 2013). A esse respeito, acreditamos que o ensino de leitura e de literatura estão ligados a uma proposta pedagógica geral de ensino, em que não seria produtivo dissociar a leitura literária da sistematização do ensino de literatura, visto que uma complementa a outra. Ademais, considerando o que Street (1984) propõe acerca dos modelos ideológico e autônomo de letramento ${ }^{2}$, apesar de os já mencionados $\mathrm{PCN}$ e a Base Nacional Comum Curricular (BNCC) proporem um ensino que esteja mais voltado ao que entendemos por modelo ideológico, é o modelo autônomo que parece ainda ser (re)produzido nas práticas pedagógicas da educação básica brasileira. Sua aplicação, como analisaremos no curta, acaba não só responsabilizando o aluno por seu "fracasso escolar" ${ }^{\prime \prime}$, mas também impedindo-o, em um primeiro momento, de se engajar em uma prática de letramento crítico, como veremos adiante.

Por ora, apesar dessas discussões do "como" performar o ensino de literatura serem bastante recorrentes, ressaltamos que ainda há quem indague se essa é uma

2. O modelo ideológico de letramento está voltado a formas de ensino e aprendizagem que contam com uma leitura crítica, contextualizada e aplicada à sociedade. O modelo autônomo de letramento, por sua vez, foca na "autonomia" do aluno perante a aprendizagem de leitura e escrita, como se esse fosse um processo completo que depende apenas do sujeito para ser desenvolvido, independentemente de sua inserção social e/ou cultural ou de suas condições materiais de acesso à educação (alimentação, transporte, higiene, entre outros).

3. Entendemos o fracasso escolar como um juízo de valor antipedagógico, principalmente porque está atrelado, de acordo com nossa experiência, mais a uma busca por individualizar culpas do que à responsabilização das instituições e à (des)construção do sistema de ensino. 
disciplina a ser ensinada na escola. Nesse sentido, acreditamos que o questionamento à "utilidade da literatura" pode nos levar a uma melhor compreensão não só dessa proposição, fazendo uma reflexão teórica, mas também do percurso crítico feito pelo protagonista do nosso objeto de análise. Destarte, para fomentar a discussão sobre essa pretensa "utilidade", valemo-nos da reflexão de Pucheu (2004):

[a] literatura serve - a quem? A literatura serve - a quê? A quem serve a literatura? A que serve a literatura? A literatura como serva? Serva, a literatura? A literatura é uma serva das intensidades de vida, tornando-se, assim, um caminho vital intensivo. E progressivo. A literatura é um caminho vital intensivo e progressivo de vida. Um dos caminhos, um caminho privilegiado. Por esse caminho, chega-se à vida, não como uma última paragem, estanque, a ser atingida, mas como o que já está, desde sempre, presente, em movimento, mas não conseguimos, habitualmente, vivenciar, não nos tornamos aptos a, cotidianamente, atualizar sua potência implícita na superfície explícita de nosso corpo rotineiro. Criando, no nosso, outros corpos, a literatura torna possível vivenciar a vida, e, tornando a vida vivível, a literatura torna a vida real (PUCHEU, 2004, p. 225).

Parece-nos que ao responder as questões que ele mesmo propõe, Pucheu (2004) amarra a literatura ao entendimento da vida, assim como à sua intangibilidade. Então, por mais que esse seja um ganho incomensurável que pode ser proporcionado pelas práticas de leitura, muitas vezes isso parece não bastar para a justificativa da manutenção desse campo de estudo na base curricular brasileira.

Alguns mencionam o desejo (presente ou ausente) individual pela leitura literária como argumento para mantê-la ou expurgá-la do currículo. Outros apontam o desenvolvimento subjetivo do aluno para que se valha alguma carga horária desse tópico (XYPAS, 2018; REZENDE, 2013). Entretanto, estamos inseridos em um sistema educativo que enfrenta reformas voltadas ao incentivo de forma(ta) ção técnica e profissional para o mercado de trabalho ${ }^{4}$. Nesse sentido, para além da reflexão sobre o desejo ou o desenvolvimento subjetivo do aluno, talvez este seja o momento de propor algumas estratégias para a manutenção da disciplina de literatura no currículo, considerando a empreitada do atual governo no que se refere à educação básica e superior no país $s^{5}$.

Afirmar, por exemplo, que a literatura não precisa servir ninguém, mas pode servir a alguma coisa (ainda que sem defini-la), pode ser uma delas. Quem sabe até alegar que a literatura serve de alguma coisa, sem correr necessariamente o "risco"

4. Disponível em: http://portal.mec.gov.br/component/content/article?id=40361. Acesso em set. 2019.

5. É possível conferir algumas das ações e dos planos do Ministério da Educação em diversas reportagens. Destacamos a que está disponível em: https://educacao.estadao.com.br/noticias/ geral,abraham-weintraub-as-polemicas-do-ministro-da-educacao,70002857628. Acesso em mai. 2020 . 
de ser servil a ideologias, possa ser também um caminho. Dentre as diferentes possibilidades trazidas por sua (in)transitividade, o verbo "servir" tem a capacidade, inclusive, de nos servir em favor e a favor do ensino de literatura. É claro que para esse tipo de defesa deixamos de fora a discussão teórica de que ideologia não é deformação, mas composição de nosso tecido social, assim como silenciamos - mas não apagamos - o potencial de desenvolvimento crítico, cidadão e humano atrelado a ela.

Nesse sentido, consideramos que

[t]alvez um dos maiores problemas da leitura literária na escola [...] não se encontre na resistência dos alunos à leitura, mas na falta de espaço-tempo na escola para esse conteúdo que insere fruição, reflexão e elaboração, ou seja, uma perspectiva de formação não prevista no currículo, não cabível no ritmo da cultura escolar, contemporaneamente aparentada ao ritmo veloz da cultura de massa (REZENDE, 2013, p. 111)

Assim, visto que os letramentos como prática social precisam levar em consideração não só os desdobramentos positivos de seu desenvolvimento, mas também o cenário em que estão inseridos ${ }^{6}$, consideramos necessário destacar a forma como é visto, na sociedade, o papel que a educação desempenha para, então, podermos refletir sobre ela e melhorá-la. Considerando o que Rezende (2013) propõe, as questões referentes à permanência ou à extinção da disciplina de literatura nas escolas precisam se voltar também ao ambiente e à estrutura escolar, afinal, não são só os tutores ou aqueles que já estão fora da escola que (re)produzem o senso comum a respeito do ensino, ele perpassa todos nós, alunos e educadores.

Destarte, uma maneira de aplicar essa forma de se voltar à literatura nas escolas é a que Neves ${ }^{7}$ propõe, em que está em voga um letramento literário. Esse tipo - e não modelo, pois isso seria demasiadamente estruturalista para o que é proposto nessa visada - de letramento não só trataria da leitura subjetiva ou literária, mas também da sua sistematização e avaliação no ensino básico regular brasileiro. A nosso ver, essa didática da literatura se faz urgente, visto que pode ser uma forma de contornar a guinada autoritária e antidemocrática que temos visto se dar globalmente, principalmente considerando que a pedagogia crítica não é "[...]

6. No Brasil, por exemplo, não só há uma desvalorização do trabalho dos professores, mas também da educação como um todo. Disponível em: https://oglobo.globo.com/sociedade/professoresbrasileiros-tem-os-piores-salarios-afirma-ocde-em-levantamento-feito-em-48-paises-23752804 e em https://economia.uol.com.br/noticias/redacao/2019/03/29/defesa-educacao-congelamentogastos.htm. Acesso em jun. 2019.

7. Ainda não há publicação de Cynthia Agra de Brito Neves sobre esse assunto, mas fazemos essa afirmação a partir de nossas anotações de uma disciplina ofertada por ela para a pós-graduação no IEL/Unicamp, durante o primeiro semestre de 2019: LP120 - Teorias de leitura. 
um método que possa ser aplicado nos colégios. É uma revisão do tipo de escola que queremos [e] uma tentativa de reconhecer que a educação é sempre política" (GIROUX, 2019, s/p). Assim, se "o tipo de pedagogia que se usa tem muito a ver com a cultura, a autoridade e o poder" (GIROUX, 2019, s/p), repensar a sala de aula com os professores e alunos é imperioso, principalmente ao considerarmos que "[a] história que contamos ou o futuro que imaginamos se reflete nos conteúdos que ensinamos" e que "é preciso desenvolver outros métodos que formem alunos capazes de desafiar as práticas antidemocráticas no futuro" (GIROUX, 2019, s/p).

Nessa toada, o curta-metragem Meu amigo Nietzsche apresenta sentidos que podem nos ajudar a pensar o ensino de leitura nas escolas e como a relação do aluno com o meio em que está inserido pode ser tanto uma oportunidade de revolucionar seu aprendizado quanto uma ameaça para o status-quo.

\section{A JORNADA DO SUPER-HOMEM: LER NIETZSCHE SENDO UM ANALFABETO FUNCIONAL}

De acordo com o relatório do Indicador de Analfabetismo Funcional (INAF) de 2018, cerca de três em cada dez brasileiros são analfabetos funcionais ${ }^{8}$. Isso significa que $30 \%$ da população brasileira apresenta dificuldade em ler e interpretar textos, assim como Lucas $^{9}$, protagonista do curta-metragem Meu amigo Nietzsche. Nesse sentido, a primeira cena que vemos no filme apresenta o protagonista cabisbaixo, ouvindo de sua professora que ele precisa treinar e melhorar a sua leitura, senão repetirá de ano. Assim, já de início, chama-nos a atenção a recomendação da professora que coloca o aluno como único responsável tanto pela sua dificuldade quanto por sua "recuperação escolar". A partir disso, considerando que o curta se vale de uma representação brasileira e de possibilidades latino-americanas do perfil dos alunos, de sua capacidade de leitura e do ambiente escolar ${ }^{10}$, a diretiva da docente parece refletir a compreensão do ensino não como uma atividade dialógica, se pensarmos com Bakhtin (2003), mas como uma atividade inserida em um modelo autônomo de letramento (STREET, 1984), conforme definimos anteriormente,

8. Disponível em: https://drive. google.com/file/d/1ez-6jrlrRRUm9JJ3MkwxEUffltjCTEI6/view. Acesso em jun. 2018.

9. O termo "analfabeto funcional" é utilizado pelo diretor do curta, Fáuston Silva, para descrever o protagonista. Disponível em: https://www.youtube.com/watch?v=q8dHpTrHdVg. Acesso em mai. 2020 .

10. O diretor do curta afirma em entrevista que se vale do contexto brasileiro para criar e desenvolver o argumento do filme, assim como seus personagens. Disponível em: https://www.youtube.com/ watch?v=q8dHpTrHdVg. Acesso em mai. 2020. 
o que parece se (re)produzir em algumas de nossas salas de aula na atualidade. É válido, ainda, apontar que sabemos que os professores da educação básica no Brasil, principalmente os das redes estadual e municipal, estão constantemente sobrecarregados de trabalho, recebem baixos salários, ensinam em escolas sem infraestrutura, têm que lidar com salas de aula superlotadas, são sugados pela burocracia etc. - somente para citar alguns dos problemas conjunturais que os afetam - e, por isso, optamos por trazer à baila a realidade escolar brasileira para analisar o curta.

Para o que se segue no filme, quando Lucas, ao tentar seguir a recomendação da professora, sai da escola disposto a ler "tudo o que vê pela frente", também é válido retomarmos os critérios que parecem ter direcionado o comentário da docente. Nos PCN temos que

[u]m leitor competente só pode constituir-se mediante uma prática constante de leitura de textos de fato, a partir de um trabalho que deve se organizar em torno da diversidade de textos que circulam socialmente. Esse trabalho pode envolver todos os alunos, inclusive aqueles que ainda não sabem ler convencionalmente (BRASIL, 1997, p. 41).

Ademais, se nos ativermos às balizas de avaliação previstas para o terceiro e quatro ciclos do Ensino Fundamental pelos PCN (BRASIL, 1998), no que se refere especificamente à língua portuguesa, vemos muitas expectativas em relação ao aluno - como ler de maneira independente sem ajuda de terceiros (BRASIL, 1998, p. 95-96), selecionar procedimentos de leitura (BRASIL, 1998, p. 96) coordenando estratégias para compreensão a partir de conhecimentos prévios (BRASIL, 1998, p. 96), entre outras -, mas poucas orientações em relação ao trabalho de mediação do docente, a não ser no que se refere a prover informações para a compreensão do texto (BRASIL, 1998, p. 96). Nesse sentido, quando Lucas se depara com um folheto da "Auto-escola Freud", vemos que o folheto não só remete à ideia de que o aluno deve resolver seus problemas escolares sozinho, se "autoensinando", como também provoca, aliado a uma cena que aparece um pouco mais adiante, em que a mãe ameaça "capar" o filho se ele repetir de ano, um outro efeito de sentido: o da castração psicanalítica (freudo-lacaniana). Nessa possibilidade de interpretação, valemo-nos do postulado de que para que o Complexo de Édipo seja dissolvido - indo, na idade de Lucas, além da percepção da diferença sexual -, o medo da castração entra em jogo para que a lei (qual seja) seja obedecida. Destarte, tanto a ameaça da professora quanto a da mãe em relação às consequências de seu nível de leitura obrigaram Lucas a buscar uma saída.

Continuando seu percurso, depois da leitura do folheto e da palavra Salomé em um muro em que havia um menino e uma menina de mãos dadas - uma alusão 
ao grande amor da vida de Nietzsche, a filósofa Lou Salomé, que optou por outro parceiro que não o autor mencionado -, vê-se, à distância, uma pipa caindo ao chão e diversas crianças indo ao seu encontro para tentar pegá-la. Enquanto Lucas e os colegas correm em direção à pipa, passam em frente a uma igreja em que o pastor diz "não vos conformeis com esse mundo", o que chama a nossa atenção ao considerarmos a crítica de Nietzsche ([1883] 2011) à religião no livro que, em seguida, será encontrado pelo menino em um lixão. Essa frase, comumente proferida por representantes de instituições religiosas, instrui/orienta/aconselha que se deve resistir às tentações mundanas para se chegar ao reino dos céus; ao contrário disso, para o filósofo alemão, além de Deus estar morto (NIETZSCHE, [1883] 2011), a inconformidade deve estar atrelada não ao futuro espiritual, mas ao presente, para que se possa deixar "o animal homem" para ser "o super-homem".

Adiante, para tentarem capturar a pipa, as crianças entram no lixão da cidade e Lucas nem chega perto de apanhá-la, pois se distrai lendo embalagens dispostas no chão, até que encontra o livro Assim falava Zaratustra (NIETZSCHE, [1883] 2011). Intrigado com o nome do autor escrito na capa, o menino vai para casa e pergunta aos seus pais o que significam aquelas palavras, mas, sem sucesso, acaba por descartar o livro numa carroça de coleta de recicláveis. Entra em cena, então, o catador de papelão dono da carroça, que vê a ação de Lucas e, após perguntar se o livro era do menino, pronuncia o nome do autor, contando-lhe um pouco sobre Nietzsche e chamando a atenção do protagonista para a importância de ler aquela obra. Ademais, o catador pontua que por mais que seja uma leitura difícil, Lucas não poderia desistir, recomendando: "se você não entender as palavras, você sai feito um doido pelo mundo perguntando pra todo mundo, pra toda gente, tá bom?". Ainda que possamos nos voltar ao fato de que um conhecedor de Nietzsche esteja trabalhando como catador de papelão - o que poderia ser uma metáfora para a figura do intelectual e do valor da educação na sociedade brasileira -, o que ele diz ao garoto remete-nos ao fato de que "[c]ompreender não é uma ação apenas linguística ou cognitiva. É muito mais uma forma de inserção no mundo e um modo de agir sobre o mundo na relação com o outro dentro de uma cultura e uma sociedade" (MARCUSCHI, 2011, p. 89, grifos do autor).

Assim, ao propor que o menino pergunte às pessoas ao seu redor o que não entender, não só o catador o incentiva a produzir novos sentidos a partir de seu contexto sociocultural, mas também indica que a interpretação de texto e o processo de significação das palavras não são dados, mas, sim, construídos. E

[é] neste sentido que a leitura crítica da realidade, dando-se num processo de alfabetização ou não e associada sobretudo a certas práticas claramente políticas de mobilização e de 
organização, pode constituir-se num instrumento para o que Gramsci chamaria de ação contra-hegemônica. (FREIRE, [1981] 1989, p. 14).

Lucas escutou, de fato, a recomendação do catador de papelão e leu o livro de Nietzsche, superando, aos poucos, as suas dificuldades de leitura. Durante essa conquista do poder de seu próprio ensino, Lucas consegue melhorar suas notas em todas as disciplinas, o que poderia se configurar como uma ação contrahegemônica, visto que a instituição escolar, representada na figura da professora, previu o fracasso do aluno e o responsabilizou por isso. Nossa proposição parece se confirmar quando a docente, mesmo parabenizando-o pelas notas, fica incomodada com a desenvoltura do aluno que, por sua vez, começa a liderar os colegas em uma jornada ao "super-homem". A professora então decide encaminhar o caso à direção, dizendo que Lucas tinha ficado "doido". Assim, levando em consideração o que se entende por loucura em nossa sociedade, apresentamos três gestos de interpretação desse significante na trama.

O primeiro se dá quando, ao questionar a mãe "se Deus está morto", Lucas é levado para uma sessão de descarrego na igreja de sua comunidade pelo receio de sua mãe de que o livro seja "coisa do cão". A loucura, então, está atrelada ao questionamento de um saber constituído e instituído socialmente como verdade - a existência de Deus, no caso. O segundo ocorre quando a professora se surpreende tanto com o fato de o menino ter lido por três vezes o que ela considera ser um livro difícil, apesar de sua graduação escolar, quanto com a desenvoltura do protagonista com os colegas, incentivando-os a deixarem de ser "animais", "homens" para serem "super-homens". É aí que a docente acredita que o aluno está "doido", sendo endossada pelo diretor da escola. Nesse caso, a loucura é vista pelos olhos de quem, conformado à sua realidade, vê o despontar da crítica como um afastamento da razão e do que se deve seguir e pensar.

Em geral, a leitura parece provocar medo não apenas pelo contato com o livro - o que já foi observado no século XIX quando do crescimento da oferta de exemplares para o público (CHARTIER, 1999, p. 110) -, mas também pelos efeitos que podem dela decorrer. Nesse sentido,

[...] o acesso à leitura e à escrita leva uma população de colegiais, e depois universitários, a abandonar a terra, ou a loja, em favor dos ofícios da pena e da palavra. Tudo isso contribui para que os poderes e os poderosos vejam nisso uma grande desordem social que enfraqueceria o Estado, já que, desviados dos ofícios da terra ou da manufatura e em busca de cargos e benefícios, os leitores que se tornam estudantes demasiado numerosos obrigam a importar do estrangeiro aquilo que não mais se produz no país. E a teoria mercantilista teme, mais do que tudo, o esgotamento da riqueza metálica do reino, dilapidada para pagar as importações. É um imaginário muito forte, enraizado nas concepções econômicas, que não concebe a ordem social a não ser como reprodução idêntica das condições passadas (CHARTIER, 1999, p. 106). 
Nessa empreitada, cabe ainda um terceiro gesto de interpretação da loucura, quando nos voltamos à fala do catador de papelão mencionada anteriormente: "e se você não entender as palavras, você sai feito um doido pelo mundo perguntando pra todo mundo, pra toda gente, tá bom?". Com Foucault ([1972] 2014), podemos apreender que aqueles que não se adequavam ou não se (con)formavam à ordem vigente nos séculos XVIII e XIX eram marginalizados e o diferente era patologizado - o que ainda podemos observar em pleno século XXI. No caso que analisamos, o doido - que também pode ser uma referência do catador a si mesmo - seria aquele que, inconformado com a realidade, com o que não compreende, questiona, desconstrói o mundo ao seu redor, buscando e catando sentidos por aí. E não seria isso uma prática de letramento crítico? Vejamos o que Souza (2011) entende por isso:

[1]er criticamente implica [...] em desempenhar pelo menos dois atos simultâneos e inseparáveis: (1) perceber não apenas como o autor produziu determinados significados que tem origem em seu contexto e seu pertencimento sócio-histórico, mas ao mesmo tempo, (2) perceber como, enquanto leitores, a nossa percepção desses significados e de seu contexto está inseparável de nosso próprio contexto e os significados que dele adquirimos. (SOUZA, 2011, p. 132).

Assim, a forma encontrada por Lucas de desenvolver, por si só, sua prática de leitura, acaba por resvalar no que compreendemos atualmente como letramento crítico, isto é, ocorre uma conscientização (FREIRE, [1992] 2005) do mundo ao seu redor enquanto o protagonista desenvolve suas práticas de leitura e de significação. Então, a partir da amizade com o livro, Lucas acaba por criar um evento de letramento crítico e, ao se apropriar do texto de Nietzsche para comentar ou avaliar sua vida e o mundo ao seu redor, desestabiliza também o que entendemos por autor, como já discutido por Foucault (2011), Barthes (1988), Chartier (2012), entre outros, quando se apropria do texto que está sendo lido.

Entretanto, poderíamos, ainda, questionar qual seria o papel da escola nesse processo. No caso do curta, temos uma instituição que acaba por confundir autonomia com culpabilização e loucura com criticidade. Na BNCC, porém, temos que o compromisso da escola seria o de

propiciar uma formação integral, balizada pelos direitos humanos e princípios democráticos, [sendo] preciso considerar a necessidade de desnaturalizar qualquer forma de violência nas sociedades contemporâneas, incluindo a violência simbólica de grupos sociais que impõem normas, valores e conhecimentos tidos como universais e que não estabelecem diálogo entre as diferentes culturas presentes na comunidade e na escola. Em todas as etapas de escolarização, mas de modo especial entre os estudantes dessa fase do Ensino Fundamental, esses fatores frequentemente dificultam a convivência cotidiana e a aprendizagem, conduzindo ao desinteresse e à alienação e, não raro, à agressividade e ao fracasso escolar (BRASIL, 2017, p. 57). 
Nesse sentido, a recomendação de que Lucas procurasse fora de escola uma "solução" para suas dificuldades de leitura, assim como o não acolhimento de sua emancipação como leitor e, por consequência, sujeito crítico, indicam uma desarticulação entre o que se prevê e o que efetivamente se pode fazer pedagogicamente em nosso país.

Ademais, quando a professora observa Lucas incentivando os colegas a serem super-homens, ela diz que ele "não é mais um menino, [...] é uma dinamite", o que nos leva a revisitar a última obra de Nietzsche, de cunho autobiográfico, Ecce bomo (NIETZSCHE, [1888] 2008), em que, com receio de ser mau interpretado e até sacralizado, o filósofo alemão retoma alguns de seus principais conceitos. Uma das frases célebres dessa obra é a afirmação: "[n]ão sou um homem, sou uma dinamite" (NIETZSCHE, [1888] 2008, p. 117), em que Nietzsche assume justamente o tipo de loucura de que Lucas é acusado: a inconformidade e a desestabilização do que é tido como verdade.

Por fim, destacamos o momento em que Lucas faz amizade com outro livro. Sua mãe revela ter jogado fora Assim falava Zaratustra (NIETZSCHE, [1883] 2011), então, decepcionado, Lucas se dirige ao lixão para tentar recuperar seu exemplar. Enquanto vasculha o local, recita "[e]scuta-me também com os teus olhos. Minha voz é um remédio até para os cegos de nascença. E quando chegares a [acordar], [acordado] ficarás eternamente" (NIETZSCHE, [1883] 2011, p. 282), e eis que encontra O manifesto comunista de Karl Marx ([1848], 2006), no qual lê: "o trabalhador nada tem a perder, a não ser suas algemas. Trabalhadores do mundo todo, univos!". Passando, nesse sentido, de um despertar filosófico - do homem que deve superar sua humanidade para chegar ao super-homem -, Lucas chega ao início da conscientização de classe. Assim, enquanto vemos o nome do curta mudar de Meu amigo Nietzsche para Meu amigo Marx antes dos créditos finais, pensamos na jornada de um analfabeto funcional que se torna um super-homem ao, na amizade com a leitura, emancipar-se de seu destino escolar revolucionando não só a si mesmo como também aqueles que estão ao seu redor e, potencialmente, a sociedade como um todo. A seguir, em um gesto de conclusão, comentaremos esse processo de Lucas como uma forma de repensarmos as aulas de leitura de literatura.

\section{SUPERAR O ANIMAL QUE SOMOS: EMANCIPAÇÃO PELA PRÁTICA CRÍTICA DE LEITURA}

Após o percurso que fizemos entre o ensino de literatura no Brasil e o evento de letramento crítico que foi a leitura de Assim falava Zaratustra (NIETZSCHE, 
[1883] 2011) para Lucas, percebemos que a loucura de se deixar transformar pelo texto literário, filosófico, ao mesmo tempo em que se altera aquilo que é lido em processos críticos de significação, apresenta perigos a um mundo conformado ao óbvio, aos saberes-poderes que se colocam ilusoriamente como inquestionáveis. Isso pode ser visto, na esfera escolar, quando há o questionamento da efetividade de um campo de estudo por sua não evidente utilidade, ou ainda, quando há a culpabilização do aluno por seu fracasso, deixando a ele o papel de suturar as lacunas existentes em seu processo de aprendizado. Dessa forma, Lucas provoca a desestabilização de algumas "verdades" quando consegue dar uma saída ao seu analfabetismo funcional - o que destacamos, aqui, como uma exceção à regra. Para além da esfera escolar, os perigos oferecidos ao óbvio parecem se manifestar, por exemplo, quando aqueles que não aceitam os sentidos já dados "inconformam-se" à estrutura dos saberes e até da sociedade ${ }^{11}$.

Nesse sentido, retomamos um discurso de Zaratustra (NIETZSCHE, [1883] 2011, p. 39), em que ele fala Das três metamorfoses do espírito humano, nesse caminho de superar o animal que é o homem. Nele, existem três figuras no processo de metamorfose: o camelo, o leão e a criança. O camelo é a primeira metamorfose, em que o animal é uma metáfora para o espírito que se assume resistente e que carrega aquilo tudo o que lhe é pesado e inalienável. Caminhando com o peso do (seu) mundo nas costas para o deserto e confrontado com sua solidão, ocorre a metamorfose do camelo em leão, que quer capturar a liberdade ao mesmo tempo em que é senhor do deserto em que vive. Assim, do animal que renuncia a si mesmo e é reverente ao outro, passa-se àquele que irá atrás de conquistar a liberdade para criar um novo mundo. A terceira metamorfose se dá quando, com essa liberdade de criação, é preciso recomeçar a vida com a inocência da criança, em um movimento sagrado de dizer sim, de se abrir para o novo e de reinventar-se.

Parece-nos que Lucas teria, com essa primeira leitura, refletido, entendido e aceitado, ainda que inconformado, a realidade ao seu redor, carregando em suas costas o primeiro passo para a reinvenção de si e do mundo. Isso, pois,

[a] leitura também [é "um derivado complexo do rosto que reflete o que ali está para ser visto"], talvez, pois o que a criança explora ou teme nos livros é em larga escala esse ser estranho, inquietante, fascinante, que está dentro dela, do qual ela ignora porções inteiras e que às vezes se revela, se constrói por acaso quando encontra uma página; esse lugar distante no interior, o mais íntimo, o mais escondido, que é, contudo, onde nós nos abrimos aos outros.

11. Refletimos sobre essa inconformidade social considerando o fato de que há uma parcela de trabalhadores não convencionais e de pessoas em situação de rua - que podem ser simbolizados na figura do catador de papelão no curta - que optam por viver fora dos padrões justamente por não acreditarem neles. Questões similares a essas podem ser lidas na dissertação de Quintão (2012). 
Aí encontra-se grande parte do segredo que procuram os leitores, às vezes freneticamente - $\mathrm{e}$ que outros, ao contrário, esforçam-se a evitar. (PETIT, 2010, p. 53).

Assim, com essa reflexão sobre o analfabetismo funcional e a possibilidade de uma saída crítica para essa fragilidade do sistema escolar, o segredo de uma leitura bem-sucedida, no caso do curta analisado, estava no investimento subjetivo de Lucas, que se deu a partir de um estímulo externo de um "professor" inusitado. Dessa forma, se "[...] o modo como imaginamos o futuro continua sempre dependendo daquilo que conhecemos" (CHARTIER, p. 139), por mais que a educação brasileira esteja "no lixão" de nossa sociedade conformada e (des)governada, há tempo de conhecermos e emanciparmos nossas formas de ler o mundo e de ensinar outros a lê-lo em um evento de letramento crítico e, por extensão, de letramento literário.

\section{REFERÊNCIAS}

BAKHTIN, Mikhail. Estética da criação verbal. São Paulo: Martins Fontes, 2003.

BARTHES, Roland. O rumor da língua. Tradução de Mário Laranjeira. São Paulo: Editora Brasiliense, 1988.

BRASIL. Ministério da Educação. Base Nacional Curricular Comum. Brasília: MEC, 2017. Disponível em index.php?option $=$ com_docman\&view $=$ download\&alias $=79611$ anexo-texto-bncc-aprovado-em-15-12-17-pdf\&category_slug=dezembro-2017pdf\&Itemid $=30192$. Acesso em jun. 2020.

BRASIL. Secretaria de Educação Fundamental. Parâmetros curriculares nacionais: língua portuguesa. Brasília: MEC/SEF, 1997.

BRASIL. Secretaria de Educação Fundamental. Parâmetros curriculares nacionais: terceiro e quarto ciclos do ensino fundamental: língua portuguesa. Brasília: MEC/SEF, 1998.

CHARTIER, Roger. A Aventura do Livro: do Leitor ao Navegador. Trad. Reginaldo de Moraes. São Paulo: Editora UNESP/ Imprensa Oficial do Estado, 1999.

CHARTIER, Roger. O que é um autor? Revisão de uma genealogia. Tradução de Luzmara Curcino; Carlos Eduardo de Oliveira Bezerra. São Carlos: EdUFSCar, 2012.

DALVI, Maria Amélia. Literatura na escola: propostas didático-metodológicas. In: DALVI, Maria Amélia; REZENDE, Neide Luzia de; JOVER-FALEIROS, Rita (orgs.). Leitura de Literatura na escola. São Paulo: Parábola, 2013. 
FOUCAULT, Michel. O que é um autor? In: FOUCAULT, Michel. Ditos e escritos III: Estética: literatura e pintura, música e cinema. Tradução de Inês Barbosa. Rio de Janeiro: Forense, 2011.

FREIRE, Paulo. A importância do ato de ler. In: A importância do ato de ler: em três artigos que se completam. 21. ed. São Paulo: Autores Associados: Cortez, (1981) 1989.

FREIRE, Paulo. Pedagogia da Tolerância. São Paulo: Editora Unesp, (1992) 2005.

GIROUX, Henry. "A crise da escola é a crise da democracia". Entrevista cedida a Ana Torres Menárguez. EL PAÍS. Barcelona, mai. 2019. Disponível em: https://brasil. elpais.com/brasil/ 2019/05/09/internacional/1557407024_184967.html. Acesso em: jun. 2019.

MARX, Karl. O manifesto comunista. Tradução de David Boyle. Rio de Janeiro: Jorge Zahar, (1848) 2006.

MENEZES DE SOUZA, Lynn Mario T. Para uma redefinição de Letramento Crítico: conflito e produção de significação. In: MACIEL, Ruberval Franco; ARAUJO, Vanessa de Assis (orgs.) Formação de professores de línguas: ampliando perspectivas. Jundiaí: Paco editorial, 2011, p. 128-140.

MEU AMIGO NIETZSCHE. Direção: Fáuston Silva. 2012. Disponível em: https://www. youtube.com/watch?v=FroyMvgYfm0. Acesso em jun. 2019.

NIETZSCHE, Friedrich. Assim falava Zaratustra: um livro para todos e para ninguém. Trad. Mário Ferreira dos Santos. 6 ed. Petrópolis: Vozes, (1883) 2011.

NIETZSCHE, Friedrich. Ecce bomo: como alguém se torna o que é. Tradução: Paulo César de Souza. São Paulo: Companhia das Letras, (1888) 2008.

PETIT, Michèlle. A arte de ler ou como resistir à adversidade. Trad. Arthur Bueno e Camila Boldrini. São Paulo: Editora 34, 2010.

PUCHEU, Alberto. Literatura, para que serve? In: Manuel Antonio de Castro (org.). A construção poética do real. 1ed. Rio de Janeiro: 7 Letras, 2004, v. 1, p. 224-242.

QUINTÃO, Paula Rochlitz. Morar na rua: há projeto possível? 2012. Dissertação (Mestrado em Arquitetura e Urbanismo, Projeto, Espaço e Cultura). Disponível em: http:// www.teses.usp.br/teses/disponiveis/16/16136/tde-07082012-122947/pt-br.php. Acesso em jun. 2019. 
REZENDE, Neide Luzia de. O ensino de literatura e a leitura literária. In: DALVI, Maria Amélia; REZENDE, Neide Luzia de; JOVER-FALEIROS, Rita (orgs.). Leitura de Literatura na escola. São Paulo: Parábola, 2013.

ROUXEL, Anne. Ousar ler a partir de si: desafios epistemológicos, éticos e didáticos da leitura subjetiva. Trad. Rosiane Xypas. Revista Brasileira de Literatura Comparada, n. 35, 2018, p. 18-25.

STREET, Brian. Literacy in theory and practice. Cambridge: Cambridge University Press, 1984.

XYPAS, Rosiane. A leitura subjetiva no ensino de literatura: apropriação do texto literário pelo sujeito leitor. Olinda, PE: Nova Presença, 2018.

Recebido: 5/2/2020

Aceito: 1/6/2020

Publicado: 20/7/2020 